\title{
Performance evaluation of multiphase flow models applied to virtual flow metering
}

\author{
K. Mokhtari \& P. J. Waltrich \\ Craft and Hawkins Department of Petroleum Engineering, \\ Louisiana State University, USA
}

\begin{abstract}
This paper presents a performance evaluation of multiphase flow models when using these models on Virtual Flow Meters (VFM). Recently, VFM simulators have been identified as a technology capable of provide metering backup, monitoring for abnormalities of physical multiphase flow meters and also for production well allocation. Nevertheless, there are just a few studies found in the literature analysing the accuracy of different VFM models applied to multiphase flow metering. In the oil and gas industry it is essential to accurately measure the amount of oil, gas and water being produced by individual wells. Prior to the 1980s, single-phase measurements alone were sufficient to meet the industry standards. However, with the advent of deepwater exploration and production, multiple wells comingling to a single production separator is a common practice in petroleum production for offshore systems. Therefore, the use of multiphase flow meters to account for the production of oil, gas and water from individual wells became evident. This investigation uses field data for more than one well to evaluate the performance VFM simulators. The results obtained from this study shows that VFM models can provide accurate predictions for multiphase flow metering. The simulators evaluated in this study could predict flow rates of oil, gas and water within acceptable levels of uncertainty, with an average absolute error of $20 \%$.
\end{abstract}

Keywords: multiphase flow metering, virtual-flow-metering, production allocation.

\section{Introduction}

In oil and gas field operations, it is essential to accurately measure flow rates of oil, gas and water produced by individual wells. The production rates from 
individual wells are used to access the productivity of each well, provide information about production decline and excessive water production. Prior to the 1980 s, single-phase measurements alone were sufficient to meet the needs of the industry [1]. At that time, the flow rates from different wells commingling to the same production separator have been measured as total flow rates, without the knowledge of individual well flow rates. These separators are able to separate the oil, gas and water phases. The outputs of the separated fluids are measured by conventional single-phase techniques, such as orifice plates for gas phase and turbine meters for oil and water phases.

In the early 1980s, the oil and gas industry started to gain interest in developing Multiphase Flow Meters (MPFMs). MPFMs are able to measure accurately the flow rates of oil, gas and water from each well and also from group of wells without separation of the phases. However, the installation and maintenance of such MPFMs are usually expensive and time consuming. For instance, MPFM are often installed in subsea production system. In case of metering failure, the access to calibrate or verification of MPFM is very difficult and can lead to months or years of erroneous flow rate measurements. Therefore, development of techniques that can help on identifying metering failure is essential [2].

One of the techniques that has started to gain some momentum in the last decade on indicating MPFM malfunction is the so-called Virtual Flow Meters or VFMs. VFMs are commercially available flow modeling software, which can be used as a backup or alternative for multiphase flowmeter devices. The greatest advantage of using VFM models is the ease of use and low cost involved to acquire and operate such modelling tools. VFM models use only mathematical models and measurements of conventional pressure and temperature sensors that are already installed in individual wells for production operation and surveillance [1, 3].

Recommended practices have recently acknowledged the fact that use of VFM model as an effective alternative for multiphase flow rate measurements, particularly in subsea systems when multiple wells are commingled to the same production separator $[4,5]$. However, the acceptance of VFM models for flow rate determination is still limited by regulatory agencies. This limited acceptance is likely due to the fact that there is still a scarce number of studies in the literature about VFM models description, validation and field verification [4]. From few studies available in the literature that validate VFM models with field data $[6,7]$ it is possible to see that these technique has shown promising results in the field for flow rate determination, with accuracy levels similar to actual flow meters. Nevertheless, more studies are still needed to evaluate VFM models in a wider range of conditions to establish the weakness and capabilities in more details.

The objective of this paper is to evaluate VFM systems over a range of multiphase flow conditions using field data. The latest recommend practices on multiphase flow measurements have not being updated in the last decade [4, 5], while VFM models have significantly improved its accuracy in the last 10 years. The VFM results analyzed in this study will be used to draw conclusions about the VFM state-of-the-art technology and not focus on recommending the advantages of any particular commercial software [4]. 


\section{Description of the VFM model used in this study}

PIPESIM simulator was used to carry out the simulation in the present study [8]. PIPESIM software package is a commercial simulator that can be used to simulate fluid flow in petroleum production systems. A model in PIPESIM can be a single well, multiple wells, flowlines and surface equipment connected to each other. PIPESIM offers multiple model for multiphase flow in pipes, valves and fluid flow in the reservoir. The several model could potentially be used as different VFM models. This study evaluates these different models using field data from a deepwater well.

There is still a gap of studies comparing different VFM models/correlation to identify the effect on VFM accuracy when using different models/correlations. There are a few different approaches currently available in commercial software which offer VFM solutions [9]. These different approaches include steady-state or transient flow simulators, based on data validation and reconciliation, using a model based on one component (such as the reservoir, wellbore, choke valves, venture, orifice, or flowlines) or a model considering many components of the system interconnected (network model). Most of the VFM models commercially available are based on the conservations of mass, momentum, and energy equations. Using these conservations equations and the measurement of pressure and temperature changes through one or more components of the system, VFM models can estimate the flow rates of oil, gas, and water. However, there are always more than one flow model for each component in the production system. Therefore, it is important to evaluate how different flow models can affect the accuracy of VFM technology.

This study uses a multiphase flow simulator software to estimate flow rates over time for a particular deepwater field [8]. The results of the flow rate determination using this multiphase flow simulator is compared to field data for different flow models for the different components of the system (network model).

\subsection{Basic physical model in PIPESIM}

The steps that are required to build the wellbore physical model are:

- Identify the appropriate model either well-centric (single well) or network centric (multiple wells).

- Set-up the fluid model either black oil or compositional [10].

- Add downhole or and surface equipment to the well if needed.

- Specify basic data that are required for each model and also specify correlations, such as wellbore geometrical configuration, reservoir temperature, and completion details.

- Select flow model to simulate each individual component in the system.

\subsection{Network model}

A schematic diagram of the network model is presented in Figure 1. The physical network model consists of four components: 
- Reservoir (source node).

- Wellbore model.

- Choke model.

- Flowline model.

- Fluid properties model.

The network model includes a fluid source (reservoir) at the bottom of the wellbore. The wellhead node is connected to the choke, which in turn is connected to a flowline. In this network model, source node is the pressure/flow rate boundary condition. The bottomhole pressure and temperature are provided through the source node. The wellbore model is constructed using completions data and wellbore deviation survey. A sink node at the end of the network model provides an outlet pressure boundary condition.

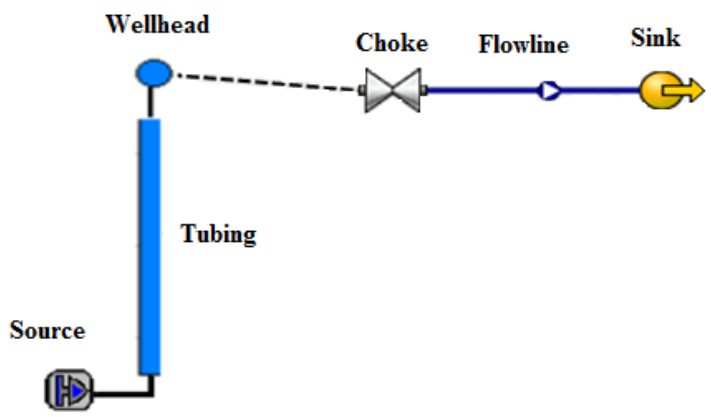

Figure 1: Schematic diagram for the network model built for this study.

\subsection{Wellbore and flowline models}

The pressure gradient equation (mechanical energy balance equation) is used for the wellbore and flowline models. This equation is derived from the combination of the conservation of mass and momentum. The conservation of mass (for a constant pipe area) for the single-phase fluid flow in a pipe together with the conservation of momentum, can be expressed as [11],

$$
\frac{d P}{d L}=-\tau \frac{\pi d}{A}-\rho g \sin \theta-\rho v \frac{d v}{d L}
$$

The idea behind VFM models is to use the measurement of pressure drop between two distinct points in the production system and then estimate the flow rate. Once the pressure drop is measured, the flow rate can be determined by varying the flow rate to match the pressure drop, as the pipe wall shear stress $(\tau)$ and the third term of the right-hand-side in equation 1 (acceleration term) are functions of the flow velocity. However, equation 1 is only valid for single-phase flow. Therefore, if more than one phase is present, this equation would have to be fundamentally solved for each phase. If oil, gas, and water are present, at least three pressure drop measurements (six pressure points) from distinct points in the system would need to be obtained to solve this problem, as this problem would have three unknowns: 
oil, gas, and water flow rates (or phase velocities). Alternatively, a fluid property model (based on vapour-liquid-equilibrium - which can determine the gas-liquid fraction in the fluid flow) and the use of the conservation of energy equation, can be used to provide two additional equations to solve this system of equations, as long as the fluid composition and temperature change measurements are available. In steady-state and single-phase flow, the conservation of energy equation can be written based on the enthalpy gradient form for a constant pipe are as [12],

$$
\frac{d h}{d L}=-Q \frac{\pi d}{w}-\rho g \sin \theta-v \frac{d v}{d L}
$$

where $w$ is the mass flow rate, and $Q$ is the heat-flux, which is defined by the overall-heat transfer coefficient $(U)$, temperature of the fluid $\left(T_{f}\right)$, and temperature of the environment $\left(T_{e}\right)$, given by the following expression,

$$
Q=U\left(T_{f}-T_{e}\right)
$$

\subsection{Selected multiphase flow models for pressure-gradient calculation}

Most of the flow models used to predict pressure drop for multiphase flow in pipes are derived from the pressure gradient equation (equation 1). The selection of these different multiphase flow models will essentially define the approach to obtain the pipe wall shear stress $(\tau)$ and the liquid holdup (liquid fraction in a pipe segment). The liquid holdup is used to determine the mixture fluid properties, such as mixture density and mixture viscosity.

In this study, Hagedorn and Brown multiphase flow model is used for the vertical wellbore and Beggs and Brill for the horizontal flowline (upstream to the choke valve) [11]. These two multiphase flow models are widely used in the oil and gas industry for multiphase flows in vertical and horizontal pipes, respectively. A sensitivity analysis was carried out with the field data obtained for this study and no significant changes in the flow rate predictions are obtained if other multiphase flow models are used for the wellbore and flowline [13].

\subsection{Fluid properties model}

As described in the previous section, a fluid properties model can be used to provide the gas-liquid-fraction based on the vapour-liquid-equilibrium theory. Fluid models are used to determine the phase state and the phase thermodynamic and transport properties such as density, viscosity and enthalpy. In the simulations in this study, black oil model is used [10]. This model is widely used in the oil and gas industry and is very useful when detailed or reliable information about the compositional of the working hydrocarbon fluid is not available (which is the case of the field data obtained for this study).

Black oil fluids can be modelled in three phases and the amount of each phase is defined at stock tank conditions by defining two distinct ratios: Gas-LiquidRatio (GLR) and Water-Cut (WC). Once the GLR and WC are defined, the black oil model provides correlations for the fluid properties such as gas and liquid densities, viscosities, compressibility factor, solution gas-oil-ratio, and gasliquid surface tension. These fluid property correlations for the block oil model are presented in detail in [10]. 


\subsection{Choke model}

The fluid velocity increases through the choke valve and this velocity for compressible fluids reach sonic velocity [14]. As the pressure difference across the choke increases, the flow velocity also increases. At the point the velocity becomes sonic, the flow is critical and it is independent of the downstream pressure [15]. In the simulation software used in this study [8], there are three correlations available for subcritical flow, and nine correlations for critical flow:

- Subcritical flow correlations: Mechanistic, Ashford-Pierce, and API-14B (which is a slight modification from the mechanistic model).

- Critical flow correlations: Gilbert, Ros, Baxendall, Archong, Pilehvari, Omana et al., Mechanistic, Poetmann-Beck, Ashford-Pierce [16], presents a description and evaluation of the correlations for Gilbert, Ros, Baxendall, Archong, Pilehvari. The latter correlations use the same basic equation but different coefficients,

$$
q_{l}=\frac{p_{u p} 64 d^{C}}{A G L R^{B}}
$$

where, $p_{u p}$ is the pressure upstream to the choke, $d$ is the choke orifice, and $q_{l}$ is the liquid flow rate. The mechanistic and API-14B models used for subcritical and critical flow is described next. A, B, and C are coefficients determined empirical and given by [16].

- Choke subcritical flow using the Mechanistic and API-14B models [8]: The pressure loss across the choke is given by the weight average of the liquid and gas phase drops,

where

$$
\Delta P=\frac{\rho_{n} \times v^{2}}{2 \times c} \times\left[\frac{\lambda_{L}}{\left(c_{v L} \times Z_{L}\right)^{2}}+\frac{\lambda_{G}}{\left(c_{v G} \times Z_{G}\right)^{2}}\right]
$$

$$
\begin{gathered}
\rho_{n}=\lambda_{L} \rho_{L}+\lambda_{G} \rho_{G} \\
v=\frac{\mathrm{q}}{\mathrm{A}_{\text {bean }} \times \rho_{\mathrm{n}}} \\
Z_{L}=1 \\
Z_{G}=1-\frac{0.41+0.35 \delta^{4}}{\gamma} \times \frac{\Delta P}{P_{u p}}
\end{gathered}
$$

where $\rho_{n}$ is the non-slip density, $v$ is the mixture velocity, $A_{\text {bean }}$ is the choke area, $\lambda_{l}$ and $\lambda_{g}$ are the liquid and gas phase flowing fractions, $Z_{l}$ and $Z_{g}$ are the liquid and gas compressibility factors, and $\gamma$ is the gas specific gravity.

For the API-14B model the gas and liquid discharge coefficients are constant values of $c_{v g}=0.9$ and $c_{v l}=0.85$, respectively. The liquid flow is assumed incompressible, and gas flow incompressible and adiabatic.

- Choke critical flow using the Mechanistic and API-14B models [8]: The correlations that are used for the choke critical flow is same as the subcritical flow correlation (mechanistic) with the addition of the following assumptions,

$$
\Delta p=\left(1-C_{P R}\right) p_{u p}
$$

where, $C_{P R}$ is the critical pressure ratio as proposed by Ashford-Pierce [16]. 


\section{Results and discussions}

\subsection{Description of the field data}

The dataset used in this study includes daily measurements of pressure and temperature at different locations of the system (bottomhole, wellhead, upstream and downstream to the choke valve), choke openings, oil, gas, and water flow rates. Limited fluid property information was also available. During the two years of production data available, fifteen evaluations points were selected. These points were selected during periods of time were flow rates are not changing significantly for at least three days, to assume steady-state conditions. The range of condition for the field dataset can be described as the following:

- Gas-Oil-Ratio: 2,000 to $4000 \mathrm{SCF} / \mathrm{BBL}$.

- Water-Cut (ratio between water and total liquid rate): $4 \%$ to $75 \%$.

- Choke opening: 13/64 to 35/64ths of an inch.

Figure 2 shows a plot of the flow rates and bottomhole pressure over time, for the different evaluations points. The actual values for this plot are removed due to the confidentiality of the field data used in this study.

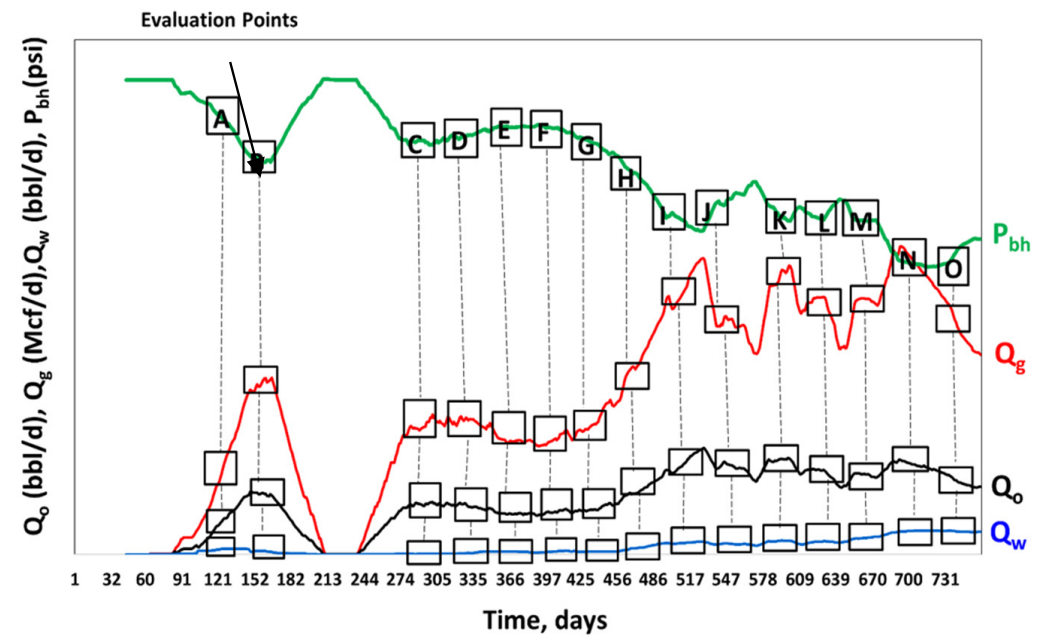

Figure 2: Production data used in this study. Each selected point corresponds to evaluations point used during the performance evaluations of the VFM models investigated in this study. $Q_{g}$ is the gas flow rate, $Q_{o}$ the oil flow rate, $Q_{w}$ the water flow rate, and $P_{b h}$ is the bottomhole pressure. 
Table 1 shows the information given to perform the flow rates predictions for Cases 1 and 2. The actual data in this table is not shown due to the confidentiality of the field data used in this study. The given data in Table 1 highlighted in green is used as input data, while the data highlighted in blue show the data that will be used to evaluate the choke correlations. The flow rates of oil, gas and water are manually varied to match as close as possible with the given data in blue (wellhead pressure and temperature). The non-highlighted data (temperature upstream to the choke and PLET) show the data not used in the flow predictions. As presented in Table 1, GOR and WC are given for two points A and B (early production data).

Table 1: $\quad$ Input data used for Cases 1 and 2.

\begin{tabular}{|c|c|c|c|c|c|c|c|c|c|c|c|c|c|}
\hline \begin{tabular}{|c|} 
Eval. \\
Points
\end{tabular} & $\begin{array}{l}\text { Allocated } \\
\text { Gas } \\
\text { (Mmcf/d) }\end{array}$ & $\begin{array}{c}\text { Allocated } \\
\text { Oil } \\
\text { (Bb/d) }\end{array}$ & $\begin{array}{l}\text { Allocated } \\
\text { Water } \\
(\mathrm{Bb} / \mathrm{d})\end{array}$ & $\begin{array}{l}\text { Allocated } \\
\text { Liquid } \\
\text { (Bb/d) }\end{array}$ & $\begin{array}{c}\text { GOR } \\
\text { (scf/stb) }\end{array}$ & $\begin{array}{c}\text { Water } \\
\text { Cut } \\
(\%)\end{array}$ & $\begin{array}{l}\text { BHP } \\
\text { (psi) }\end{array}$ & $\begin{array}{l}\text { BHT } \\
\text { (F) }\end{array}$ & $\begin{array}{c}\text { WHP } \\
(p s i)\end{array}$ & $\begin{array}{c}\text { WHT } \\
\text { (F) }\end{array}$ & $\begin{array}{l}\text { Choke } \\
\text { (/64ths) }\end{array}$ & $\begin{array}{c}\text { Plet } \\
\text { Pressure } \\
\text { (psi) }\end{array}$ & $\begin{array}{c}\text { Plet } \\
\text { Temp } \\
\left({ }^{\circ} \mathrm{F}\right)\end{array}$ \\
\hline $\mathrm{A}$ & & & & & $\mathrm{X}$ & $\mathrm{X}$ & $\mathrm{X}$ & $\mathrm{X}$ & $\mathrm{X}$ & $\mathrm{X}$ & $\mathrm{X}$ & $\mathrm{X}$ & $\mathrm{X}$ \\
\hline B & & & & & $\mathrm{X}$ & $X$ & $X$ & $X$ & $X$ & $X$ & $\mathrm{X}$ & $X$ & $\mathrm{X}$ \\
\hline $\mathrm{C}$ & & & & & & & $\mathrm{X}$ & $\mathrm{X}$ & $X$ & $\mathrm{X}$ & $\mathrm{X}$ & $\mathrm{X}$ & $\mathrm{X}$ \\
\hline D & & & & & & & $\mathrm{X}$ & $\mathrm{X}$ & $X$ & $\mathrm{X}$ & $\mathrm{X}$ & $\mathrm{X}$ & $\mathrm{X}$ \\
\hline$E$ & & & & & & & $X$ & $X$ & $X$ & $X$ & $X$ & $X$ & $X$ \\
\hline$F$ & & & & & & & $X$ & $\mathrm{X}$ & $X$ & $\mathrm{X}$ & $\mathrm{X}$ & $\mathrm{X}$ & $\mathrm{X}$ \\
\hline $\mathrm{G}$ & & & & & & & $X$ & $\mathrm{X}$ & $X$ & $\mathrm{X}$ & $\mathrm{X}$ & $\mathrm{X}$ & $\mathrm{X}$ \\
\hline $\mathrm{H}$ & & & & & & & $\mathrm{X}$ & $\mathrm{X}$ & $\mathrm{X}$ & $\mathrm{X}$ & $\mathrm{X}$ & $\mathrm{X}$ & $\mathrm{X}$ \\
\hline I & & & & & & & $\mathrm{X}$ & $\mathrm{X}$ & $X$ & $\mathrm{X}$ & $\mathrm{X}$ & $\mathrm{X}$ & $\mathrm{X}$ \\
\hline $\mathrm{J}$ & & & & & & & $X$ & $X$ & $X$ & $\mathrm{X}$ & $\mathrm{X}$ & $X$ & $\mathrm{X}$ \\
\hline $\mathrm{K}$ & & & & & & & $\mathrm{X}$ & $\mathrm{X}$ & $\mathrm{X}$ & $\mathrm{X}$ & $\mathrm{X}$ & $\mathrm{X}$ & $\mathrm{X}$ \\
\hline $\mathrm{L}$ & & & & & & & $\mathrm{X}$ & $\mathrm{X}$ & $\mathrm{X}$ & $\mathrm{X}$ & $\mathrm{X}$ & $\mathrm{X}$ & $\mathrm{X}$ \\
\hline $\mathrm{M}$ & & & & & & & $\mathrm{X}$ & $\mathrm{X}$ & $\mathrm{X}$ & $\mathrm{X}$ & $\mathrm{X}$ & $X$ & $\mathrm{X}$ \\
\hline $\mathrm{N}$ & & & & & & & $X$ & $\mathrm{X}$ & $X$ & $\mathrm{X}$ & $\mathrm{X}$ & $\mathrm{X}$ & $\mathrm{X}$ \\
\hline $\mathrm{O}$ & & & & & & & $X$ & $\mathrm{X}$ & $X$ & $X$ & $X$ & $\mathrm{X}$ & $\mathrm{X}$ \\
\hline
\end{tabular}

\subsection{Description of Cases 1 and 2}

Two different cases are defined in this study to evaluate the different multiphase flow models applied to VFM:

- Case 1: Table 1 shows the 15 evaluations points (A to O) selected from production history with bottomhole pressure (BHP) and temperature (BHT), wellhead pressure (WHP) and temperature (WHT), upstream (WHP) and downstream (PLET) choke pressures and temperatures. Gas-Liquid-Ratio (GOR) and Water Cut (WC) for two initial points (A \&B) are also provided as input data.

- $\quad$ Case 2: The same as Case 1 but with the additional information about the well Productivity Index (PI).

The simulation branch is started from the reservoir-well through the sink (downstream of the choke). Inflow Performance Relationship (IPR) model IPR is used to model the flow of the fluids from the reservoir through the formation and into the wellbore. PIPESIM offers a detailed list of IPRs for both oil and gas reservoirs. Well PI relationship for liquid reservoirs is the simplest and the most widely used IPR equation, which is used here. It states that the liquid rate is directly proportional to pressure drawdown between the bottom hole and the reservoir [12]. 


$$
Q_{L}=P I \times\left(P_{R}-P_{w f}\right)
$$

where, $Q_{L}$ is the stock-tank liquid rate, $P_{R}$ is the reservoir pressure, $P_{w f}$ is the bottomhole pressure, $P I$ is the productivity index. The value obtained from field data through formation evaluation analysis used is 0.715 barrels/psi.

\subsection{Evaluation of choke valve correlations}

PIPESIM was not originally designed as a Virtual Flow Metering (VFM) tool. However, this software package is used here as a VFM model, where oil, gas and water flow rate prediction were tuned manually without the use of an automatic system to match the information given in Table 1 . Therefore, further improvement in the prediction results would be expected in all cases if an automatic system uses similar models. Nevertheless, the prediction trends are expected to be within reasonable agreement with other automatic VFM systems.

Sensitivity analysis were performed for the choke model. There are 3 models for sub-critical and 9 models for critical conditions at the choke. Therefore, to obtain the model that best fits the production data, two models for sub-critical (Mechanistic and Ashford) and three models (Mechanistic, Gilbert, and Ashford) were used for critical flow in the choke. A list of the models used in the sensitivity analysis is presented in Table 2. These selected models were used to predict pressure and temperature upstream to the choke for all evaluation points in Table 1. Then, the difference (error percentage) between the calculated and measured pressure and temperature upstream to the choke is obtained. After that, the error for each evaluation point can be calculated to obtain the cumulative error for the prediction of each model, as presented in Table 2. The choke model with least cumulative error is selected to use in the flow rates prediction.

The results from Table 2 match with previous studies on evaluations of twophase flow through choke valves [17]. The work of Surbey et al. [17] have concluded that mechanist models show better accuracy when compared to experimental data on the prediction of mass flow rate and pressure drop for a wide range of conditions. The large deviation on temperature prediction is likely due to

Table 2: Cumulative error percentages between calculated and measured wellhead pressured and temperatures for different sets choke correlations for all evaluation points.

\begin{tabular}{|c|l|l|c|c|}
\hline \multirow{4}{*}{$\begin{array}{c}\text { Correlation } \\
\text { Pairs }\end{array}$} & \multicolumn{2}{|c|}{ Choke Corrolations } & \multicolumn{2}{c|}{ Cumulative Error \% } \\
\cline { 2 - 3 } & Sub-Critical & \multicolumn{1}{|c|}{ Critical } & & \\
\cline { 2 - 3 } & Mechanistic & Mechanistic & WHP & WHT \\
\hline 1 & Mechanistic & Mechanistic & 2.66 & 84.21 \\
\hline 2 & Mechanistic & Gilbert & 26.68 & 176.04 \\
\hline 3 & Mechanistic & Ashford & 24.56 & 267.69 \\
\hline 4 & Ashford & Mechanistic & 23.05 & 100.41 \\
\hline 5 & Ashford & Gilbert & 56.25 & 124.53 \\
\hline 6 & Ashford & Ashford & 3.32 & 88.32 \\
\hline
\end{tabular}


the poor sensitivity to temperature change prediction in the choke valve models. As the temperature change is highly dependent of the overall heat transfer coefficient and Joule-Thompson effect, these two parameters are difficult to estimate for complex geometries and multicomponent fluids, which is the case of hydrocarbons flow through choke valves.

\subsection{Evaluation results for Cases 1 and 2}

Figures 3 show the errors for the prediction results for Cases 1 and 2 for evaluation points $\mathrm{A}$ through $\mathrm{O}$ for oil and gas flow rates, and water-cut. The main difference between Case 1 and Case 2 is the addition of the IPR model in Case 2. For Case 2 , more models than needed are available. In other words, in Case 2 we have 4 models (IPR, wellbore, choke, and fluid model) and we have three unknowns: oil, gas and water flow rates. In this case, the IPR model is used to predict oil rate, the choke model to predict gas rate and wellbore model (base on conservation of energy in the wellbore) was used to estimate water cut. The fluid model was not used directly here to tune the flow rates prediction.

As can be seen in Figure 3, the main difference between the results of Cases 1 and 2 is the water-cut predictions. That is probably a consequence of the inclusion of the IPR model. In Case 2, it is difficult to predict if the assumption of the fix PI is reasonable. So, it is difficult to anticipate between Cases 1 and 2, which one would give more accurate predictions of WC. Since we are not sure about the accuracy of the PI value provided and it would be affected over time, we would expect that the results for Case 1 are more accurate than Case 2. It is also widely known that the PI varies with time for most reservoirs. Therefore, the addition of a reservoir model using a constant PI show worse results, than not including this additional model. Considering the average error of flow rates prediction for oil and gas, the VFM model used here estimated the flow rates with approximately $20 \%$ accuracy. The prediction of water-cut is larger than $20 \%$, but is likely due to the poor prediction of fluid temperature as shown in Table 2. The water-cut is a stronger function of the temperature prediction, as the water has larger heat capacity than oil and gas.

\section{Conclusions}

The following conclusions can be drawn from the results obtained from the flow rate prediction and matching approach:

1. Different wellbore multiphase flow models do not seem to have a significant impact on the estimated flow rates.

2. Different choke models show a large impact on pressure and temperature prediction through the choke valve. The mechanistic model provides better prediction when compared to field data. This conclusion has been previously reached by other authors in the literature.

3. Temperature data was primarily used to predict water cut in our simulations. Wellhead temperature has a larger sensitivity to water content than to oil and gas, as the heat carrying capacity of water is significantly larger for water than for oil and gas. 
4. Overall, the VFM model used in this study show reasonable predictions of the flow rates for oil and gas, with average error of approximately $20 \%$. The prediction of water-cut show significantly larger errors. This result is likely due to the poor prediction of temperature change through the choke valve.

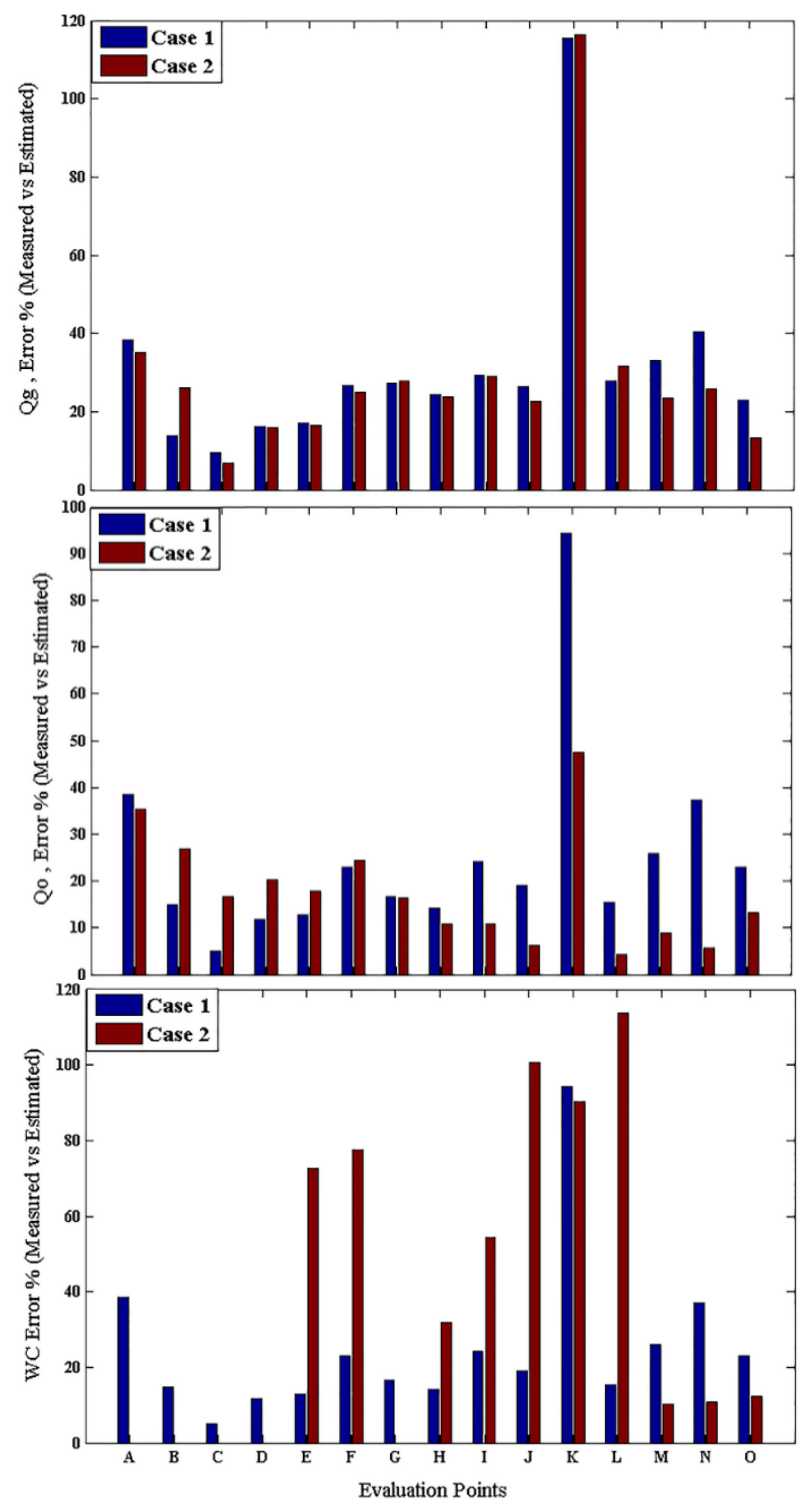

Figure 3: Error for Cases 1 and 2 for the comparisons between VFM model predictions and field data: (a) gas flow rate, (b) oil flow rate, and (c) water-cut rates. 
5. However, more detailed studies are needed to further investigate the root cause of poor predictions of water-cut.

6. The addition of a reservoir model based on a constant productivity index (PI) show worse results than the VFM without the reservoir model. These poor results for the VFM model with constant PI is likely due to that fact that productivity index vary with time. Therefore, the conclusions here suggest that the reservoirs models used for VFM tools should consider productivity index varying with time.

\section{References}

[1] Falcone, G., G.F. Hewitt, and C. Alimonti, Multiphase Flow Metering: Principles and Applications. 2009: Elsevier Science.

[2] Jenson, F., A Substitute for Test Separators, in 24289-MS SPE Conference Paper. 1992, Society of Petroleum Engineers.

[3] Toskey, E.D., Improvements to Deepwater Subsea Measurements RPSEA Program: Evaluation of Flow Modelling. 2012, Offshore Technology Conference.

[4] (API), A.P.I., API Recommended Practice for Measurement of Multiphase Flow. 2005, API Publishing Services, 1220 L.

[5] Corneliussen, S.e.a., Handbook of Multiphase Flow Metering. 2005: Norwegian Society for Oil and Gas Measurement (NFOGM).

[6] Haldipur, P. and G.D. Metcalf, Virtual Metering Technology Field Experience Examples. 2008, Offshore Technology Conference.

[7] Melbø, H., et al., Software That Enables Flow Metering of Well Rates With Long Tiebacks and With Limited or Inaccurate Instrumentation. 2003, Offshore Technology Conference.

[8] PIPESIM, PIPESIM Multiphase Flow Simulator Manual. 2013, Schlumberger.

[9] Amin, A., Evaluation of Commercially Available Virtual Flow Meters (VFMs). 2015, Offshore Technology Conference.

[10] McCain, W.D., The Properties of Petroleum Fluids. 1990: PennWell Books, 1990.

[11] Brill, J.P. and H.K. Mukherjee, Multiphase Flow in Wells. 1999: Henry L. Doherty Memorial Fund of AIME, Society of Petroleum Engineers Incorporated.

[12] James P. Brill, H.K.M., Multiphase Flow in Wells. 1999: Henry L. Doherty Memorial Fund of AIME, Society of Petroleum Engineers, 1999.

[13] Hagedorn, A.R. and K.E. Brown, Experimental Study of Pressure Gradients Occurring During Continuous Two-Phase Flow in Small-Diameter Vertical Conduits. 940-PA SPE Journal Paper 1965.

[14] Michael J. Economides, A.D.H., Christine Ehlig-Economides, Ding Zhu, Petroleum Production Systems (2nd Edition) 2012: Pearson Education.

[15] Sachdeva, R., et al., Two-Phase Flow Through Chokes, in 15657-MS SPE Conference Paper. 1986, Society of Petroleum Engineers. 
[16] Abdul-Majeed, G.H. and R.A.-A. Maha, Correlations Developed To Predict Two-Phase Flow Through Wellhead Chokes, in 88-39-26 PETSOC Conference Paper. 1991, Petroleum Society of Canada.

[17] Surbey, D.W., B.G. Kelkar, and J.P. Brill, Study of Multiphase Critical Flow Through Wellhead Chokes. 15140-PA SPE Journal Paper, 1989. 